$\sqrt{3}$

J. Bio-Sci. 26: 31-40, 2018

ISSN 1023-8654

http://www.banglajol.info/index.php/JBS/index

\title{
DIETARY DIVERSITY SCORE AND SOCIO-ECONOMIC FACTORS OF STUNTING AMONG PRE-SCHOOL CHILDREN IN RAJSHAHI CITY, BANGLADESH
}

\author{
K Yeasmin ${ }^{1}$, L Bari², KMS Islam ${ }^{3}$ and T Yeasmin ${ }^{4 *}$ \\ IInstitute of Biological Sciences, University of Rajshahi, Bangladesh \\ ${ }^{2}$ Department of Food Technology and Nutritional Science, Mawlana Bhasani Science and Technology \\ University, Tangail, Bangladesh \\ ${ }^{3}$ Rajshahi Medical College Hospital, Rajshahi, Bangladesh \\ ${ }^{4}$ Department of Biochemistry and Molecular Biology, University of Rajshahi, Bangladesh
}

\begin{abstract}
In the developing countries, stunting has been the most tenacious public health problem and is the major cause of child mortality and global disease burden, where $80 \%$ of this burden is found in developing countries and would result in $22 \%$ loss of adult income. The aim of this study was to investigate prevalence and determinant factors associated with stunting among pre-school children in Rajshahi City, Bangladesh. A multi-stage cross sectional study was performed during the period March 2017 to September 2017. One thousand and nine (1009) pre-school children (36 $\leq$ Age $\leq 71$ months) were considered as our study population. Data were collected by using a pretested and semi-structured questionnaire, which consisted of socio-economic characteristics, dietary and feeding pattern related information. Stunting of a child was determined using the WHO Multicenter Growth Reference Standard. Chi-square test and multiple logistic regressions were carried out to identify determinants of stunting. The odds ratio (OR) with a 95\% confidence interval was calculated to assess the strength of the association, and $p$-value of $<0.05$ were considered as statistically significant. Boys $(52 \%)$ with mean age $53.56 \pm 10.405$ months and girls $(48 \%)$ with mean age $51.67 \pm 10.934$ months were participated. The prevalence of stunting among the preschool children in Rajshahi City was $39.7 \%$ (5.4\% severe, $24.9 \%$ moderate and $9.4 \%$ mild stunted). The odds of being stunted were illiterate mother, lower food purchasing capabilities, poor dietary diversity score (95\% Cl: 1.640-3.052; $p<0.001)$, experiencing prelacteal (95\% Cl: 1.616-2.789; $\mathrm{p}<0.001)$, prevalence of disease frequency $(95 \% \mathrm{Cl}: 1.62-3.56 ; p<0.01)$, poor socio-economic class (95\% Cl: 2.83- 9.51; $p<0.01)$.
\end{abstract}

Key words: Cross sectional study, Multiple logistic regression, Pre-lacteal, Pre-school children, Stunting

\section{Introduction}

In the developing countries, stunting has been the most tenacious public health problem and is the major cause of child mortality and global disease burden, where $80 \%$ of this burden is found in developing countries and would result in $22 \%$ loss of adult income (Tariku et al. 2016). Stunting, chronic malnutrition is caused due to long term exposure to restricted nutrient supply and frequent infection (Stevens et al. 2012). Although changes in dietary pattern, consciousness about food quality and increasing economic growth of Bangladesh have contributed to decline in rates of child stunting, more than one-third of children, aged less than 5 years still suffer from impaired linear growth, which is the most pressing problem for health. According to the recent global estimates, 165 million (26\%) children under 5 years are stunted (Black et al. 2013) of which more than $90 \%$ stunted children of the world are living in Africa and Asia, with the prevalence of $36 \%$ and $27 \%$, respectively (De Onis et al. 2012). For the future development of the country, it is fundamental to

*Author for correspondence: yeasmin_bio@yahoo.com 
ensure the optimal growth and development of infants and young children. Stunting is one of the most important public health concerns in developing countries, including Bangladesh that reflects the poor linear growth accumulated during the prenatal and postnatal period, results of poor health and nutrition. It is associated with reduced mental capacity, school performance, increased susceptibility to infectious diseases, attenuated cognitive ability and increased behavioral problems during childhood (Berkman et al. 2002) and stances an adverse functional consequences, nutritional related diseases, lost productivity and low working capability during the adolescent and adulthood period (Jukes et al. 2002).

Poverty, food insecurity, lack of parental education are associated with stunting in Bangladesh as elsewhere; nevertheless, children belonging to the richest wealth quintiles households are also stunted which is $21 \%$ and about one-third of children of literate mothers also suffer from stunting (Jesmin et al. 2011). Therefore, it is still not clear to find out the etiology of stunting, although various studies carried out using data from Bangladesh suggest that stunting is associated with the condition including poor maternal nutrition, low birth weight (LBW), severe food insecurity, inappropriate and insufficient complementary feeding, poverty, illiteracy, poor sanitation, and hygiene practices (Ahmed et al. 2012, Psaki et al. 2014). There is increasing evidence that environmental enteropathy is one cause of malabsorption of nutrients and stunting, happening when hygiene and sanitation practices are poor and young children are chronically exposed to bacteria in the environment. Determining the magnitude of stunting among preschool children, who are the new entrants of school in the near future, might provide a baseline evidence for better estimation of functional concerns, including poor cognition, and find out a way for overcoming this situation (Zewdu 2012, Fekadu et al. 2015). By analyzing these baseline survey data, the aim of this study was to investigate prevalence and determinant factors (socio-economic, demographic, and dietary) associated with stunting among pre-school children in Rajshahi City.

\section{Materials and Methods}

A community based cross sectional and household level study was performed in Rajshahi City during the period March 2017 to September 2017. Rajshahi City located at north-western part of the Bangladesh and separated from India by Padma River. The total land area of the district is 2425.37 square $\mathrm{km}^{2}$ with a population 2,699,688 as per the 2011 (Bangladesh Bureau of Statistics 2011) including the urban population of the district and one of the highest poverty zones in Bangladesh. We considered here only the city corporation area, consisted of 30 wards. By using simple random sampling techniques, we selected 20 wards for our survey. Fifty five households were chosen in each ward using a random number table. In the present study, pre-school children ( $36 \leq$ Age $\leq 71$ months) were considered as our study population. The minimum sample size was determined using the formula to estimate single population proportion with the following assumptions: the expected prevalence of stunting as 50\%, a $95 \%$ confidence level, and $5 \%$ margin of error (d). Finally, a minimum sample size of 692 was obtained after antedating a 20\% non-response rate and adjusting design effect of 1.5. For collecting more accurate result a total of 1100 households with preschool children were targeted. However, 91 parents and children were not agreed to participate in this study. As a result, we took 1009 children in our study. We collected the written consent from the household heads. If the households contained two or more preschool children, we considered one.

Data were collected by using a pretested and semi-structured questionnaire, consisted of socio-demographic and economic, health, dietary and feeding pattern related information. There were 21 consumer products included in the questionnaire ranging from a fan to a television and car; dwelling features, indicating to wealth. The score were summed and households were divided into five economic classes as follows: 1-5 = poor economic class; 6-10 = lower- middle class; 11-15 = upper-middle class; and 16-21 = high-economic class. Dietary diversity score of (DD) the child was determined using 24 hours recall method by asking 
mothers to make a list of all food items which are taken by the children in the previous 24 hours happening execution the survey. In case of mixed dish, the ingredients of the food items were listed by the mother. Then, illustrated food items were classified into seven food groups, as starchy staples (grains, roots, and tubers) and nuts and seeds; legumes; vitamin-A rich fruits and vegetables; other fruits and vegetables; egg; dairy products (milk, yoghurt, and cheese); and flesh foods (meat, fish, poultry, and organ meats) (WHO 2010). A child with a DDS of less than four food items was classified as poor dietary diversity.

Child weight was measured to the nearest $0.1 \mathrm{~kg}$ by the seca beam balance with light clothing and no shoes. Instrument calibration was carried out before weighing each child and additionally, the weighing scale was checked daily against a standard weight for its accuracy. Height was measured using the seca vertical height scale standing upright in the middle of the board to the nearest $0.1 \mathrm{~cm}$. The child's head, shoulders, buttocks, knees, and heels touched the vertical board. Birth day of study participants was extracted from the birth registration certificate of the child. Height-for-age Z-scores (HAZ), was calculated using the WHO Multicenter Growth Reference Standard. Children with a measurement of <-1 SD (-1.99 SD to -1.00 SD), <-2 SD (-2.99 SD to $-2.00 \mathrm{SD})$ and $<-3 \mathrm{SD}(\leq-3.00 \mathrm{SD})$ units from the median of the reference population were considered as mild stunted, moderate stunted and severely stunted respectively (WHO 2009). Then in this study, stunting status, the outcome variable was distributed as 0 for "Not Stunted" and 1 for "Stunted". Various socio-economic and dietary diversity score were treated as independent variable. Descriptive Statistics was carried out for calculating the prevalence of stunting of preschool children. Chi-square test was used for selecting significant independent variables for logistic regression model. Finally, binary multiple logistic regression was utilized to ascertain the influence of socio-economic factor and DDS on Stunting of children. All the statistical analyses were performed by using Statistical Package for Social Sciences (IBM SPSS version 22.0) software.

\section{Results and Discussion}

\section{Socio-economic and demographic characteristics of the data in the present study}

Five hundred and twenty five (52\%) of boys with mean age $53.56 \pm 10.405$ months and four hundred and eighty four (48\%) of girls with mean age $51.67 \pm 10.934$ months were participated in this empirical study. More than half of the mother was housewives and above one tenth of the mothers had no education. About two third of the children were belonging to poor DDS, however, early initiation of breast feeding and experiencing exclusive breast feeding by the children was $74 \%$ and $62 \%$ respectively. The habit of discarding colostrum is lower (18\%), whereas, pre-lacteal was continuing by one third of the population in the current study. Nearly one fifth and half of the people were using unsafe water and unhygienic toilet respectively. Nearly half (45\%) families were earning below 10000 BDT per month. Almost three fourth of children had suffered from diseases during the last three months before the survey and halves of children were getting complementary foods $<4$ times in a day (Table 1 ). 
Table 1. Socio- economic characteristics of selected children

\begin{tabular}{|c|c|c|}
\hline Variables & Frequency & Percentage (\%) \\
\hline \multicolumn{3}{|l|}{ Mother's occupation } \\
\hline Housewife & 556 & 55.1 \\
\hline Labour & 90 & 8.9 \\
\hline Service & 143 & 14.2 \\
\hline Others & 220 & 21.8 \\
\hline \multicolumn{3}{|l|}{ Dietary diversity score of children } \\
\hline$<4$ & 747 & 74.0 \\
\hline$>=4$ & 262 & 26.0 \\
\hline \multicolumn{3}{|c|}{ Initiation of breastfeeding (within one hour after birth) } \\
\hline Early Initiation & 746 & 73.9 \\
\hline Late initiation & 263 & 26.1 \\
\hline \multicolumn{3}{|l|}{ Exclusive breast feeding } \\
\hline No & 387 & 38.4 \\
\hline Yes & 622 & 61.6 \\
\hline \multicolumn{3}{|l|}{ Discarding colostrum } \\
\hline Yes & 190 & 18.8 \\
\hline No & 819 & 81.2 \\
\hline \multicolumn{3}{|l|}{ Pre-lacteal } \\
\hline Yes & 307 & 30.4 \\
\hline No & 702 & 69.6 \\
\hline \multicolumn{3}{|l|}{ Type of water } \\
\hline Unsafe & 183 & 18.1 \\
\hline Safe & 826 & 81.9 \\
\hline \multicolumn{3}{|l|}{ Toilet facility } \\
\hline Hygienic & 554 & 54.9 \\
\hline Unhygienic & 455 & 45.1 \\
\hline \multicolumn{3}{|c|}{ Diseases frequency in the last three months } \\
\hline No disease & 425 & 42.1 \\
\hline $1-3$ & 383 & 38.0 \\
\hline $4-6$ & 201 & 19.9 \\
\hline \multicolumn{3}{|c|}{ Frequency of giving complementary food } \\
\hline$<4$ & 460 & 45.6 \\
\hline $4-6$ & 549 & 54.4 \\
\hline \multicolumn{3}{|l|}{ Father's education } \\
\hline No education & 141 & 14.0 \\
\hline Primary and secondary incomplete & 325 & 32.2 \\
\hline $\mathrm{SSC}$ and $\mathrm{HSC}$ & 225 & 22.3 \\
\hline Higher education & 318 & 31.5 \\
\hline \multicolumn{3}{|l|}{ Mother's education } \\
\hline No schooling & 133 & 13.2 \\
\hline Primary and secondary incomplete & 369 & 36.6 \\
\hline SSC and HSC & 255 & 25.3 \\
\hline Higher education & 252 & 25.0 \\
\hline \multicolumn{3}{|l|}{ Family income } \\
\hline BDT $4000-10000$ & 450 & 44.6 \\
\hline BDT 11000 - 20000 & 268 & 26.6 \\
\hline BDT 21000 - 40000 & 220 & 21.8 \\
\hline BDT Above 40000 & 71 & 7.0 \\
\hline
\end{tabular}




\section{Prevalence of stunting among pre-school children in Rajshahi City, Bangladesh}

Table 2 showed that the prevalence of stunting among the preschool children in Rajshahi City was $39.7 \%$ ( $5.4 \%$ severe, $24.9 \%$ moderate and $9.4 \%$ mild stunted). Similar outcome pattern was observed by a study performed by Das and Gulshan (2017). They found that the prevalence of stunting in overall Bangladesh was $36.2 \%$. The result was consistent with the Mini Ethiopian Demographic and Health Survey report (40\%) conducted by Central Statistical Authority [Ethiopia] and ORC Macro (2014), and the research of Muller et al. (2005) reported the average estimate of stunting for developing countries (42.7\%), such as India (43\%), found by Sinha et al. (2012), Nigeria (44.9\%) estimated by Aliyu et al. (2012). The prevalence of stunting was more frequent among girls than boys in this empirical study, however opposite results were observed by Fakir (2015) and equivocal results were shown by Chiabi et al. (2011).

Table 2. Prevalence of stunting among pre-school children in Rajshahi city (gender wise)

\begin{tabular}{lccccc}
\hline \multirow{2}{*}{ Gender } & \multicolumn{5}{c}{ Nutritional status according to height for age - Z score } \\
\cline { 2 - 6 } & Severe stunted & $\begin{array}{c}\text { Moderate } \\
\text { stunted }\end{array}$ & Mild stunted & Normal & $\begin{array}{c}\text { Well } \\
\text { nourished }\end{array}$ \\
\hline Boys (525) & $22(4.2 \%)$ & $109(20.8 \%)$ & $46(8.8 \%)$ & $300(57.1 \%)$ & $48(9.2 \%)$ \\
\hline Girls (484) & $32(6.6 \%)$ & $142(29.3 \%)$ & $49(10.1 \%)$ & $221(45.7 \%)$ & $40(8.3 \%)$ \\
\hline Total (1009) & $54(5.4 \%)$ & $251(24.9 \%)$ & $95(9.4 \%)$ & $521(51.6 \%)$ & $88(8.7 \%)$ \\
\hline
\end{tabular}

Association between socio-demographic, economic, dietary diversity score and stunting of preschool children

In this study, chi-square test $\left(x^{2}\right)$ was used to determine the association between children's stunting and socio economic and demographic factors and dietary diversity score. In Table 3, the association between stunting and housing condition, parental occupation, education, and age, pre-lacteal, discarding colostrum, initiation of breast feeding, exclusive breast feeding, family income, expenditure for food, frequency of given complementary food, disease frequency are statistically significant $(p<0.001)$. Whereas, Das and Gulshan (2017), found that the factors significantly associated $(p<0.001$ ) with stunting are age of child, place of residence, division, parental education and occupation, mother's body mass index (BMI), wealth index, toilet facility, number of living children and birth order. The low maternal educational status was associated with higher odds of childhood stunting, observed in the study of Aliyu et al. (2012). Our study showed similar verdicts with their studies where illiterate mothers have $77 \%$ stunted children. The children, who were habituated with rich dietary diversity score had remarkably less stunted than their counterparts. The switch from exclusive breastfeeding to family foods, defined as complementary feeding among the period from 6 to 18 - 24 months of age, which is a very vulnerable period as malnutrition starts in many infants in this period due to proper knowledge of caregivers and adequacy of giving complementary food to the children is significantly responsible for high prevalence of mortality and morbidity in children under five years of age world-wide. In our study, the children achieved complementary foods (4 - 6 times) per day were not stunted (76\%) (Table 3). 
Table 3. Association between socio-demographic, economic, DDS and stunting of pre-school children

\begin{tabular}{|c|c|c|c|c|c|}
\hline \multirow[t]{2}{*}{ Variables } & \multirow{2}{*}{$\begin{array}{c}\text { Group of variables } \\
\qquad(\mathrm{N}, \%)\end{array}$} & \multicolumn{2}{|c|}{ Stunting } & \multirow[b]{2}{*}{$x^{2}$-test } & \multirow[b]{2}{*}{$p$-value } \\
\hline & & $\begin{array}{c}\text { Not stunted } \\
\mathrm{N}(\%)\end{array}$ & $\begin{array}{l}\text { Stunted } \\
\mathrm{N}(\%)\end{array}$ & & \\
\hline \multirow[t]{4}{*}{ Socio-economic class } & Poor economic class (449) & $212(47.2)$ & $237(52.8)$ & \multirow[t]{4}{*}{64.22} & \multirow[t]{4}{*}{$P<0.001$} \\
\hline & Lower middle class (283) & $188(66.4)$ & $95(33.6)$ & & \\
\hline & Upper middle class (198) & $143(72.2)$ & $55(27.8)$ & & \\
\hline & High economic class (79) & $65(82.3)$ & $14(17.7)$ & & \\
\hline \multirow[t]{2}{*}{ Dietary diversity score } & $<4(743)$ & $414(55.7)$ & $329(44.3)$ & \multirow[t]{2}{*}{26.07} & \multirow[t]{2}{*}{$\mathrm{P}<0.001$} \\
\hline & $>=4$ (262) & 193 (73.7) & 69 (26.3) & & \\
\hline \multirow[t]{2}{*}{ Discarding colostrum } & Yes (190) & $68(35.8)$ & $122(64.2)$ & \multirow[t]{2}{*}{58.32} & \multirow[t]{2}{*}{$P<0.001$} \\
\hline & № (818) & $539(65.9)$ & $279(34.1)$ & & \\
\hline \multirow[t]{2}{*}{ Initiation of breastfeeding } & Early initiation (746) & $474(63.5)$ & $272(36.5)$ & \multirow[t]{2}{*}{12.86} & \multirow[t]{2}{*}{$P<0.001$} \\
\hline & Late initiation (263) & $134(51.0)$ & $129(49.0)$ & & \\
\hline \multirow[t]{2}{*}{ Exclusive breastfeeding } & № (387) & $183(47.3)$ & $204(52.7)$ & \multirow[t]{2}{*}{44.10} & \multirow[t]{2}{*}{$P<0.001$} \\
\hline & Yes (622) & $425(68.3)$ & $197(31.7)$ & & \\
\hline \multirow[t]{2}{*}{ Pre-lacteal } & Yes (307) & $146(47.6)$ & $161(52.4)$ & \multirow[t]{2}{*}{29.77} & \multirow[t]{2}{*}{$P<0.001$} \\
\hline & No (702) & $462(65.8)$ & $240(34.2)$ & & \\
\hline \multirow{2}{*}{$\begin{array}{l}\text { Frequency of giving } \\
\text { complementary food }\end{array}$} & $<4(460)$ & $192(41.7)$ & $268(58.3)$ & \multirow[t]{2}{*}{121.06} & $P<0.001$ \\
\hline & $4-6(549)$ & $416(75.8)$ & $133(24.2)$ & & \\
\hline Giving colostrum to the baby & No (259) & $132(51.0)$ & $127(49.0)$ & 12.56 & $P<0.001$ \\
\hline & Yes (750) & $476(63.5)$ & $274(36.5)$ & & \\
\hline Type of water & Unsafe (183) & $75(41.0)$ & $108(59.0)$ & 34.67 & $P<0.001$ \\
\hline & Safe (826) & $533(64.5)$ & $293(35.5)$ & & \\
\hline Toilet facility & Hygienic (554) & $407(73.5)$ & $147(26.5)$ & 89.49 & $P<0.001$ \\
\hline & Unhygienic (455) & $201(44.2)$ & $254(55.8)$ & & \\
\hline Environmental sanitation & Hygienic (556) & $421(75.7)$ & $135(24.3)$ & 123.62 & $P<0.001$ \\
\hline & Unhygienic (453) & $187(41.3)$ & $266(58.7)$ & & \\
\hline Frequency of diseases within & No disease (425) & $311(73.2)$ & $114(26.8)$ & 51.17 & $P<0.001$ \\
\hline the last three months & $1-3(383)$ & $195(50.9)$ & $188(49.1)$ & & \\
\hline & 4-6 (201) & $102(50.7)$ & $99(49.3)$ & & \\
\hline Father's education & No Education (141) & $50(35.5)$ & $91(64.5)$ & 67.16 & $P<0.001$ \\
\hline & $\begin{array}{l}\text { Primary and secondary } \\
\text { incomplete (325) }\end{array}$ & $174(53.5)$ & $151(46.5)$ & & \\
\hline & SSC and HSC (225) & $160(71.1)$ & $65(28.9)$ & & \\
\hline & Higher education (318) & $224(70.4)$ & $94(29.6)$ & & \\
\hline Father's occupation & Service (327) & $231(70.6)$ & $96(29.4)$ & 64.58 & $P<0.001$ \\
\hline & Business (286) & $192(67.1)$ & $94(32.9)$ & & \\
\hline & Labour (125) & $51(40.8)$ & $74(59.2)$ & & \\
\hline & Farmer (116) & $44(37.9)$ & $72(62.1)$ & & \\
\hline & Others (155) & $90(58.1)$ & $65(41.9)$ & & \\
\hline Mother's education & No schooling (133) & $31(23.3)$ & $102(76.7)$ & 120.06 & $P<0.001$ \\
\hline & $\begin{array}{l}\text { Primary and secondary } \\
\text { incomplete (369) }\end{array}$ & $204(55.3)$ & $165(44.7)$ & & \\
\hline & SSC and HSC (255) & $197(77.3)$ & $58(22.7)$ & & \\
\hline & Higher education (252) & $176(69.8)$ & $76(30.2)$ & & \\
\hline
\end{tabular}


Contd.

\begin{tabular}{|c|c|c|c|c|c|}
\hline \multirow[t]{4}{*}{ Mother's occupation } & House wife (556) & $358(64.4)$ & $198(35.6)$ & 65.04 & \multirow[t]{4}{*}{$P<0.001$} \\
\hline & Labour (90) & $36(40.0)$ & $54(60.0)$ & & \\
\hline & Service (143) & $115(80.4)$ & 28 (19.6) & & \\
\hline & Others (220) & $99(45)$ & $121(55)$ & & \\
\hline \multirow[t]{2}{*}{ Mother's height } & $<=148 \mathrm{~cm}(380)$ & $103(27.1)$ & $277(72.9)$ & \multirow[t]{2}{*}{279.76} & \multirow[t]{2}{*}{$P<0.001$} \\
\hline & $>148 \mathrm{~cm}(629)$ & $505(80.3)$ & $124(19.7)$ & & \\
\hline \multirow[t]{3}{*}{ Birth weight of children } & $<2500$ gm (465) & $207(44.5)$ & $258(55.5)$ & \multirow[t]{2}{*}{97.09} & \multirow[t]{2}{*}{$P<0.001$} \\
\hline & 2500 - 3500 gm (488) & $350(71.7)$ & $138(28.3)$ & & \\
\hline & $>3500 \mathrm{gm}(56)$ & $51(91.1)$ & $5(8.9)$ & & \\
\hline \multirow{4}{*}{$\begin{array}{l}\text { Food purchasing capabilities } \\
\text { (in Taka) }\end{array}$} & $2000-4500(340)$ & $146(42.9)$ & $194(57.1)$ & \multirow[t]{4}{*}{81.22} & \multirow[t]{4}{*}{$P<0.001$} \\
\hline & $5000-9000(341)$ & $213(62.5)$ & $128(37.5)$ & & \\
\hline & $10000-20000(280)$ & $206(73.6)$ & $74(26.4)$ & & \\
\hline & Above 20000 (48) & $43(89.6)$ & $5(10.4)$ & & \\
\hline \multirow[t]{4}{*}{ Family income (in Taka) } & $4000-10000(450)$ & $213(47.3)$ & $237(52.7)$ & \multirow[t]{4}{*}{68.727} & \multirow[t]{4}{*}{$P<0.001$} \\
\hline & $11000-20000(268)$ & $177(66.0)$ & $91(34.0)$ & & \\
\hline & $21000-40000(220)$ & $155(70.5)$ & $65(29.5)$ & & \\
\hline & Above 40000 (71) & $63(88.7)$ & $8(11.3)$ & & \\
\hline
\end{tabular}

\section{Effect of stunting and socio-demographic and health nutritional factors of pre-school children}

To define the contribution of the associated factors on stunting of pre-school children in Bangladesh, we fitted logistic regression model. In Table 4, binary multiple logistic regression model demonstrated that mothers whose height $>148 \mathrm{~cm}$ had 0.109 times $(95 \% \mathrm{Cl}: 0.076-0.156 ; p<0.001)$ more probability of getting tall children as compared the mothers whose height $\leq 148 \mathrm{~cm}$. Children with birth weight $>2500 \mathrm{gm}$ were 0.229 times (95\% Cl: $0.075-0.697 ; p<0.01$ ) more likely to be not stunted children than the children with birth weight $<2500 \mathrm{gm}$. The children feed breast milk within the period of 6 months without any discontinuation had comparatively less chance $(95 \% \mathrm{Cl}: 0.400-0.843 ; p<0.01)$ to be stunted than their counterparts. Accordingly, the likelihood of stunting among children whose dietary diversity score $<4$ (95\% Cl: 1.640 3.052; $p<0.001$ ) was 2.213 times more frequent as compared to their counterparts with rich DDS. Likewise the odds of stunting was 0.287 times less (95\% Cl: $0.157-0.527 ; p<0.001)$ among children who got colostrum as the starting food of their lives, in comparison to the children who didn't get colostrum. Furthermore, children who were welcoming by honey or water or mustard oil after birth, at a sense experiencing pre-lacteal $(95 \% \mathrm{Cl}: 1.616-2.789 ; p<0.001)$ had 2.423 times higher chance to get stunted as compared with children without pre-lacteal experience. Children grown with appropriate frequencies of complementary feeding would have less $(95 \% \mathrm{Cl}: 0.204-0.425 ; p<0.001)$ unintended to be stunted than children with lower frequency of complementary feeding. Risk of receiving stunted children were 0.281 times, 0.116 times and 0.182 times higher among uneducated mother than educated mothers $(95 \% \mathrm{Cl}: 0.164$ $0.481, p<0.001),(95 \% \mathrm{Cl}: 0.058-0.232, \mathrm{p}<0.001),(95 \% \mathrm{Cl}: 0.074-0.445, p<0.001)$. Children, suffering from diseases (1-3 times) were 2.402 times $(95 \% \mathrm{Cl}: 1.62$ - 3.56; $p<0.001)$ more vulnerable for stunting than the children, not suffered from diseases during the last three months of this survey. Children from poor economic class (95\% Cl: 2.83 - 9.51; $p<0.001)$ and lower middle economic class (95\% Cl: $1.25-4.39 ; p<0.01)$ had 5.19 and 2.34 times higher probabilities to be stunted than the children belonging high economic class. Similar study was performed by Tariku et al. (2016) and found in multivariable analysis, the odds of stunting was higher among children whose families had no latrine ( $\mathrm{OR}=1.6,95 \% \mathrm{Cl}: 1.1-2.2)$, household with more than four family size $\mathrm{OR}=1.4,95 \% \mathrm{Cl}: 1.1-1.9$ ). Das and Gulshan (2017) also observed odds of being 
stunted were urban area $(O R=1.226, p$-value $=0.004)$, no or primary education of father $(O R=1.318, p$ value $<0.001)$, no or primary education of mother $(O R=1.22$, $p$-value $=0.002)$, underweight mothers $(O R=$ 1.76, $p$-value $<0.001)$ and wealth index poorest $(\mathrm{OR}=2.892$, $\mathrm{p}$-value $<0.001)$.

Table 4. Effect of stunting and socio-demographic, health related nutritional factors of pre-school children

\begin{tabular}{|c|c|c|c|c|c|c|}
\hline \multirow[t]{2}{*}{ Variables } & \multirow[t]{2}{*}{ Co-efficients } & \multirow[t]{2}{*}{$\mathrm{SE}$} & \multirow[t]{2}{*}{ p-value } & \multirow[t]{2}{*}{ OR } & \multicolumn{2}{|c|}{$95 \% \mathrm{Cl}$ of $\mathrm{OR}$} \\
\hline & & & & & Lower & Upper \\
\hline \multicolumn{7}{|l|}{ Mother's height } \\
\hline$>148 \mathrm{~cm}$ vs $\leq 148 \mathrm{~cm}^{\mathrm{R}}$ & -2.219 & 0.184 & 0.000 & 0.109 & 0.076 & 0.156 \\
\hline \multicolumn{7}{|l|}{ Children's birth weight } \\
\hline $2500-3500 \mathrm{gm}$. vs $<2500 \mathrm{gm}^{\mathrm{R}}$ & -0.062 & 0.204 & 0.762 & 0.940 & 0.630 & 1.402 \\
\hline$>3500 \mathrm{gm}$. vs <2500 gm & -1.475 & 0.569 & 0.009 & 0.229 & 0.075 & 0.697 \\
\hline \multicolumn{7}{|l|}{ Exclusive breastfeeding } \\
\hline Yes vs $\mathrm{No}^{\mathrm{R}}$ & -0.543 & 0.190 & 0.004 & 0.581 & 0.400 & 0.843 \\
\hline \multicolumn{7}{|l|}{ Dietary diversity score } \\
\hline$<4$ vs $>=4 R$ & 0.805 & 0.158 & 0.000 & 2.123 & 1.640 & 3.052 \\
\hline \multicolumn{7}{|l|}{ Discard colostrum } \\
\hline $\begin{array}{l}\text { No vs yes }{ }^{R} \\
\text { Pre-lacteal }\end{array}$ & -1.247 & 0.309 & 0.000 & 0.287 & 0.157 & 0.527 \\
\hline Yes vs noR & 0.753 & 0.139 & 0.000 & 2.423 & 1.616 & 2.789 \\
\hline \multicolumn{7}{|l|}{ Frequency of complementary feeding } \\
\hline $4-6$ times vs $<4$ & -1.223 & 0.188 & 0.000 & 0.294 & 0.204 & 0.425 \\
\hline \multicolumn{7}{|c|}{ Disease frequency during the last three months } \\
\hline $1-3$ vs No disease ${ }^{R}$ & 0.876 & 0.201 & 0.000 & 2.402 & 1.621 & 3.561 \\
\hline 4-6 vs No disease ${ }^{R}$ & 0.268 & 0.253 & 0.289 & 1.308 & 0.796 & 2.149 \\
\hline \multicolumn{7}{|l|}{ Toilet facility } \\
\hline Unhygienic vs Hygienic $^{R}$ & 0.482 & 0.241 & 0.046 & 1.619 & 1.010 & 2.595 \\
\hline \multicolumn{7}{|l|}{ Food purchasing capabilities (in Taka) } \\
\hline 5000 - 9000 vs 2000 - $4900^{R}$ & $0-.436$ & 0.221 & 0.048 & 0.647 & 0.420 & 0.996 \\
\hline \multirow{2}{*}{$\begin{array}{l}10000-20000 \text { vs } 2000-4900^{R} \\
\text { Above } 20000 \text { vs } 2000-4900^{R}\end{array}$} & -1.009 & 0.377 & 0.008 & 0.365 & 0.174 & 0.764 \\
\hline & -1.307 & 0.788 & 0.097 & 0.271 & 0.058 & 1.268 \\
\hline \multicolumn{7}{|l|}{ Mother's education } \\
\hline $\begin{array}{l}\text { Primary and secondary incomplete vs } \\
\text { No education }{ }^{R}\end{array}$ & -1.271 & 0.275 & 0.000 & 0.281 & 0.164 & 0.481 \\
\hline $\mathrm{SSC}$ and HSC vs No education ${ }^{\mathrm{R}}$ & -2.154 & 0.354 & 0.000 & 0.116 & 0.058 & 0.232 \\
\hline Higher education vs No education ${ }^{R}$ & -1.704 & 0.457 & 0.000 & 0.182 & 0.074 & 0.445 \\
\hline \multicolumn{7}{|l|}{ Socio-economic index } \\
\hline Poor economic class vs HECR & 1.647 & 0.309 & 0.000 & 5.190 & 2.830 & 9.519 \\
\hline Lower middle class vs HECR & 0.853 & 0.320 & 0.008 & 2.346 & 1.252 & 4.396 \\
\hline Upper Middle class vs HECR & 0.580 & 0.335 & 0.083 & 1.786 & 0.927 & 3.441 \\
\hline
\end{tabular}

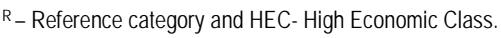




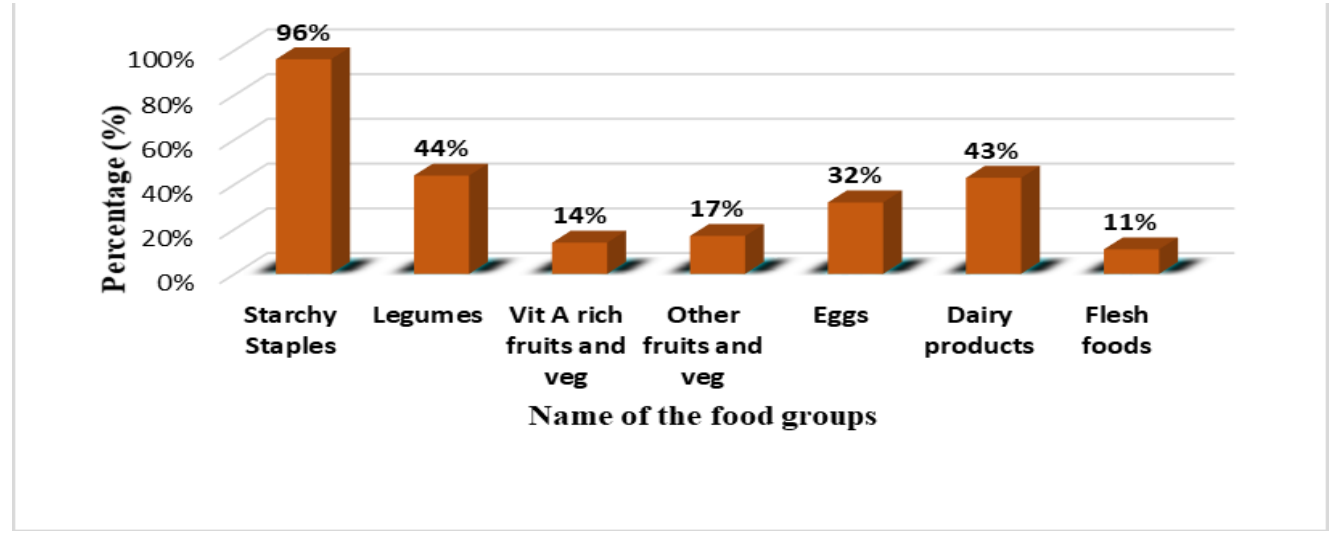

Fig. 1. Dietary diversity score among pre-school children in Rajshahi city

Maximum number (96\%) of pre-school children in Rajshahi City had taken starchy staples (rice, bread, potato, pasta etc.) whereas; intake of legumes (pulses, peas, kidney beans, lentils, black beans, etc.) and dairy products (milk, yogurt, card, cheese, etc.) were $44 \%$ and $43 \%$ respectively. Taking Vit A rich and other fruits and vegetables were not noteworthy. Only $32 \%$ children used to eat eggs daily. Awareness about health and accelerating nutrition based knowledge among household heads and caregivers are necessary for dietary diversity and preventing malnutrition among pre-school children in Rajshahi City, Bangladesh.

\section{Conclusion}

Though Bangladesh has achieved outstanding results in steady reducing the malnutrition rates among children by applying intervention programs, the findings of this study revealed that the prevalence of stunting was $39.7 \%$, suggested the scope of further improvement of the child nutritional status in Rajshahi City, Bangladesh. As stunting is a major health problem, immediate steps should be given to improve the educational sectors and to create consciousness among household head and caregivers about increasing and proper utilization of family income in the city. So, government and non-government organizations should take initiative for reducing the problem.

\section{Acknowledgment}

The authors would like to express their sincere gratitude to those children and their parents for their willingness, positive collaboration and active participation for being part of the study. The authors' heartfelt thanks will also go to the Institute of Biological Sciences for their active help.

\section{References}

Ahmed AMS, Ahmed T, Roy SK, Alam N and Hossain MI (2012). Determinants of under nutrition in children under 2 years of age from rural Bangladesh. Indian Pediatrics, 49: 821-824.

Aliyu AA, Oguntunde OO, Dahiru T and Raji T (2012). Prevalence and determinants of malnutrition among Pre-School Children in Northern Nigeria. Pakistan Journal of Nutrition, 11(11): 1092-1095.

Bangladesh Bureau of Statistics (2011). Population Census Reports.

Berkman DS, Lescano AG, Gilman RH, Lopez SL and Black MM (2002). Effects of stunting, diarrhoeal disease and parasitic infection during infancy on cognition in late childhood: a follow-up study. Lancet, 359: 564-571. 
Black RE, Victora CG, Walker SP, Bhutta ZA, Christian P, De Onis M, Ezzati M, Grantham-McGregor S, Katz J and Martorell R (2013). Maternal and child under nutrition and overweight in low-income and middle-income countries. Lancet, 382(9890): 427-451.

Central Statistical Authority [Ethiopia] and ORC Macro. Mini Ethiopia Demographic and Health Survey (2014). Addis Ababa. Maryland: Ethiopia and Calverton; https://www.unicef.org/ethiopia

Chiabi A, Nemb D, Kobelab M, Mbuagbawc L, Obamad TM and Ekoeb T (2011). Anthropometric measurements of preschool children in North Cameroon. Eastern Journal of Medicine, 16 (4): 240-247.

Das S and Gulshan J (2017). Different forms of malnutrition among under five children in Bangladesh: a cross sectional study on prevalence and determinants. BioMed Central Nutrition, 3: 1.

De Onis M, Brown D, Blossner M and Borghi E (2012). Levels and trends in child malnutrition. UNICEF-WHO-The World Bank joint child malnutrition estimates. https://www.popline.org

Fakir AMS and Khan MWR (2015). Determinants of malnutrition among urban slum children in Bangladesh. Health Economics Review, 5: 22.

Fekadu Y, Mesfin A, Haile D and Stoecker BJ (2015). Factors associated with nutritional status of infants and young children in Somali Region, Ethiopia: a cross- sectional study. BMC Public Health, 15: 846.

Jesmin A, Yamamoto SS, Malik AA and Haque MA (2011). Prevalence and Determinants of Chronic Malnutrition among Preschool Children: A Cross-sectional Study in Dhaka City, Bangladesh. International Centre for Diarrhoeal Disease Research, Bangladesh. Journal of Health, Population and Nutrition, 29(5): 494-499.

Jukes M, McGuire J, Method F and Sternberg R (2002). Nutrition: A Foundation for Development. ACC/SCN, Geneva, Switzerland, http://www.unscn.org.

Muller O, Krawinkel M (2005). Malnutrition and health in developing countries. Canadian Medical Association Journal, 73(3): 279-286.

Psaki S, Seidman J, Miller M, Gottlieb M, Bhutta Z and Ahmed T (2014). Measuring socioeconomic status in multicountry studies: results from the eight-country MALED study. Population Health Metrics, 12(1): 8.

Sinha NK, Maiti K, Samanta P, Das DC and Banerjee P (2012). Nutritional status of 2-6 year old children of Kankabati grampanchayat, Paschim Medinipur district, India: West Bengal. Sri Lanka Journal of Child Health, 41(2): 60-64.

Stevens GA, Finucane MM, Paciorek CJ, Flaxman SR, White RA and Donner AJ (2012). Trends in mild, moderate, and severe stunting and underweight, and progress towards MDG 1 in 141 developing countries: a systematic analysis of population representative data. Lancet, 380 (9844): 824-834.

Tariku A, Woldie H, Fekadu A, Adane AA, Ferede AT and Yitayew S (2016). Nearly half of pre-school children are stunted in Dembia district, Northwest Ethiopia: a community based cross sectional study. Archives of Public Health, 74: 13.

WHO (2010). Indicators for assessing infant and young child feeding practices Part 3 Country Profiles. http://www.who.int.

World Health Organization (2009). WHO child growth standards and the identification of severe acute malnutrition in infants and children: joint statement by the World Health Organization and the United Nations Children's Fund. http://www.who.int/nutrition

Zewdu S (2012). Magnitude and factors associated with malnutrition of children under five years of age in Rural Kebeles of Haramaya, Ethiopia. Harar Bulletin of Health Science, 4: 221-232. 